\title{
LA CUENCA ALTA DEL ADAJA (ÁVILA): VARIEDAD LITOLÓGICA
}

\author{
María Jesús SÁNCHEZ MUÑOZ \\ Departamento de Geografia.Universidad de León
}

La Cuenca Alta del Adaja ocupa una posición central dentro del gran conjunto de la Meseta. Desde el punto de vista geográfico se ubica en la Región Central Española, inmediatamente al SW de la ciudad de Ávila, formando parte del Sistema Central, al norte del Macizo de Gredos. Comprende una superficie de 740 $\mathrm{km}^{2}$, repartidos en 25 términos municipales de desiguales dimensiones. Cartográficamente, se localiza en las hojas del Mapa Topográfico Nacional, a escala 1:50.000 (S.G.E.: Hojas 15-21 (530) Vadillo de la Sierra, 16-21 (531) Ávila de Los Caballeros, 17-21 (532) Las Navas del Marqués, 15-22 (555) Navatalgordo y 16-22 (556) Navaluenga; entre los $4^{\circ} 30^{\prime}$ y los $5^{\circ} 15^{\prime}$ de longitud oeste y entre los $40^{\circ} 28^{\prime}$ y $40^{\circ} 40^{\prime}$ de latitud norte.

A pesar de la relativa sencillez de un relieve de orientación general ENEWsW, éste participa de tres grandes unidades morfológicas: a) la Fosa del Adaja o del Amblés de dirección ENE, es la unidad que más sobresale (tiene una altitud comprendida entre los 1.065 y los $1.200 \mathrm{~m}$.); b) la vertiente septentrional de La Paramera-Serrota (La Serrota marca el límite suroccidental de la comarca, y destaca por ser la unidad donde se encuentra la máxima altitud: el Cerro el Santo, con $2.294 \mathrm{~m}$.); la Sierra de Paramera, cuya línea de cumbres isoaltitudinales se extiende a lo largo de todo el límite meridional de la comarca (de dirección ENEWsw, culmina en el Pico Zapatero a $2.160 \mathrm{~m}$.), desciende paulatinamente hacia el este al entrar en contacto con La Cuerda de Los Polvisos, de dirección NE-Sw, que marca la transición entre la Sierra de Gredos y la Sierra de Guadarrama; c) la vertiente meridional de la Sierra de Ávila (modesto relieve cuyo límite máximo alcanza los $1.728 \mathrm{~m}$. en el Cerro Gorría), es una sierra de culminaciones planas y escasa altitud, y presenta la misma dirección que La Cuerda de Los Polvisos en su parte más occidental, para adoptar en las cercanías de Ávila una clara dirección E-W.

Prácticamente la totalidad de la Cuenca Alta del Adaja está formada por rocas plutónicas pertenecientes al zócalo Paleozoico o Macizo Hespérico, destacando su aparente uniformidad litológica que sólo se rompe por la existencia de materiales metamórficos en algunas zonas y por la presencia de materiales sedimentarios en las áreas deprimidas; así pues, dentro de este conjunto geológico podemos distinguir varias unidades litológicas: 1) materiales metamórficos (preordovícicos), 2) rocas plutónicas y filonianas (materiales hercínicos), 3) depósitos sedimentarios (terciarios) y 4) depósitos de recubrimiento (cuaternarios).

Polígonos, nº 9, 1999, pp. 183-202. 


\section{MATERIALES METAMÓRFICOS: PREORDOVÍCICOS (ES- QUISTOS Y PARANEISES).}

En la Cuenca Alta del Adaja los materiales más antiguos están presentes en afloramientos de rocas metamórficas, datados como Precámbrico-Cámbrico; materiales que hemos englobado en una calificación más generalista como "preordovícicos". Las rocas predominantes -esquistos, neises, micacitas, cuarcitas...constituyen afloramientos dispersos y de pequeña extensión entre los que destacan los bloques de la Sierra de Yemas y Tornadizos, y otros de menor magnitud, situados al norte de Villatoro y al sureste de Solosancho (Villaviciosa).

Esta litología se corresponde con los materiales que algunos autores identificaron como los "tramos de micacitas y migmatitas, con esquistos y cuarcitas" de la Sierra de Yemas (GARCÍA DE FIGUEROLA ET AL, 1983: 66), siendo este bloque el afloramiento principal, limitado en su mayor parte por granitoides intrusivos y en su borde norte por materiales terciarios del Valle Amblés. La litología de la Sierra de Yemas es compleja, pues está formada por esquistos micáceos y paraneises de tonos oscuros (datados como precámbricos) que bordean la masa granítica del batolito que aparece en el núcleo de la sierra, muestran el típico contacto intrusivo entre las rocas metamórficas y las hercínicas, por lo que los esquistos en conjunto aparecen más metamorfizados, tectonizados, con pliegues muy apretados e intensamente recristalizados en las zonas próximas a los granitoides. Estas rocas se encuadran en el "complejo laminar pegmatoide, Serie del Álamo".

Al este del Valle Amblés se localiza otro bloque de materiales metamórficos, en las cercanías de Tornadizos, siendo la prolongación del Macizo de La CañadaCebreros. Al igual que en la Sierra de Yemas estos materiales afloran en las zonas próximas a los granitos, por lo que parece estar afectado por metamorfismo de contacto, pues nos encontramos con granitos adamellíticos de grano medio a grueso con tránsito gradual a neises más o menos esquistosos de color azulado, e incluso con bandas de cuarcita y pizarras. Se trata de "neises de composición pelítica, fajeados oscuros y con abundantes segregaciones de cuarzo. Encima existe una potente serie de micacitas y pizarras con intercalaciones de metagrauwacas, anfibolitas y calizas gris azuladas con lechos siliceos", materiales que han sido datados como pre-Ordovícico (FUSTER Y MORA 1970: 317). Estas rocas metamórficas junto con los diques porfídicos que en muchos casos los atraviesan, son explotadas para la obtención de áridos por trituración que son utilizados en la construcción de carreteras, siendo la cantera más importante de este tipo la localizada en el término de Tornadizos.

\section{MATERIALES HERCÍNICOS.}

Están constituidos por rocas graníticas (granitos, adamellitas y granodioritas) y filonianas (diques de cuarzo, de pórfido y aplíticos), todas ellas formadas durante la orogenia hercínica por fusión de rocas preexistentes en la zona profunda de la cordillera en formación. 


\subsection{Los Granitoides.}

Son las rocas que más abundan en los bordes serranos de la Cuenca Alta del Adaja. Dentro de esta formación plutónica la más extendida es el "granito adamellítico de dos micas, normalmente biotítico, variando la composición mineralógica entre la de una granodiorita y la de una adamellita"l. . Nosotros no vamos a centrarnos en las diferencias de composición, sino que vamos a realizar una clasificación desde el punto de vista de las características que tienen mayor influencia morfológica; así podemos distinguir, dentro de los granitoides que aparecen en nuestra zona, los siguientes grupos: a) Granitoides de grano fino: ortoneises leucogranitos de grano fino. b) Granitoides de grano medio biotítico: granodioritas y adamellitas. c) Granitoides de grano grueso: leucogranitos de grano grueso tipo Puerto de Villatoro. d) Caleño. Alteración de granitos.

\section{1.a. Granitoides de grano fino.}

La mayor parte de la Sierra de Yemas está formada por ortoneises (granitos de dos micas), atravesados por numerosos diques de pegmatitas y de cuarzo. Se caracterizan por estar deformados en alguna fase de la orogenia hercínica, ya que su formación debió ser anterior a las últimas fases de deformación (son, por tanto, intrahercínicos). GARCÍA DE FIGUEROLA et al. (1983: 37-38) analizaron este tipo de formaciones para interpretar la génesis de los granitoides de feldespato alcalino, así como los fenómenos de metamorfismo de la región, definiendo la Sierra de Yemas como "elevaciones sobre una peña de granito de feldespato alcalino que luego ha sido fracturada por la tectónica terciaria... Las láminas de granitos de grano fino y pegmatitas se sitúan entre niveles de micacitas, porfiroides algunos niveles de migmatitas y neises fémicos. Una gran parte de las elevaciones lo constituyen granitos tectonizados similares a los granitos ruiniformes que por su cartografía se suponen formando una lámina". UBANELL (1977: 10), denominó a este granito de la Sierra de Yemas como "granito de dos micas pregranito biotítico estructurado... y su emplazamiento es posterior a la fase 2 de deformación hercínica y anterior a la fase 3", encontrando semejanzas con otro afloramiento situado en las cercanías del Puerto de Menga, al sureste, en Robledillo, si bien a éste lo califica como "granito de dos micas sin estructurar... ya que en ciertas zonas le asemejan más a una anatexita que a un granito".

Morfológicamente parece existir una relación entre el relieve de la cumbre y la litología, así quedan en resalte las rocas más resistentes (ortoneises), formando los picos, cabezas o culminaciones de las cumbres más elevadas de la Sierra de Yemas (Cabañas 1.469 m., Peñas Blancas, $1.421 \mathrm{~m}$.); mientras que sobre los esquistos, paraneises... se desarrolla la cumbre alomada y plana con su vertiente cubierta por alteritas y coluviones. A partir de estos materiales se forman pedreras de grandes bloques, pues el neis se fractura dando "canchos" gruesos, con un característico color rosado (si están oxidados en superficie), que incluso parecen

\footnotetext{
${ }^{1}$ ArRiBAS, A. Y JimÉneZ, E. (1972): Memoria del mapa geológico de España, Escala 1:200.000, Ávila. Igme, ${ }^{\circ}$ 44. Madrid.
} 
pizarras por su tendencia a romperse en lajas.

En la Cuenca Alta del Adaja, asociados a los granitoides de grano medio, aparecen afloramientos de extensión reducida de leucogranitos de grano fino, destacando el macizo situado entre Cabeza Perdiguera y Cerro Sorejado (al noroeste entre Villatoro y Poveda) y otros pequeños enclaves al noreste del Collado de Mengamuñoz. Morfológicamente, esta litología, que se distingue por sus colores claros, favorece el desarrollo de formas curvas y pedreras con pequeños tors y bolos amontonados, poco elevados, similares a los que se desarrollan sobre los neises, aunque estos granitos de grano fino aparecen más alterados que los neises. Se extienden por La Sierra de Ávila y en torno a Villatoro, donde se desarrolla una topografía de cumbres de formas curvas (Pico Prado Redondo, 1.637 m., Peña Bermeja, $1.581 \mathrm{~m}$., los Guijos, $1.578 \mathrm{~m}$.), coronadas por formas más simples, como apilamientos de bloques, tors, piedras caballeras etc., procedentes de la destrucción "in situ" de esas formas en bóveda y en cúpula.

\section{1.b. Granitoides de grano medio. Adamellitas.}

Los plutones de composición adamellítica constituyen el volumen batolítico principal de la Cuenca Alta del Adaja, puesto que las adamellitas de grano medio ocupan la mayor extensión dentro del área de estudio, desde La Sierra de Ávila, Cuerda de Los Polvisos y Parameras. Son rocas graníticas postorogénicas, cuyos magmas se formaron durante la orogénesis (procedentes de fundidos peralumíni$\cos$ ), pero se intruyeron y cristalizaron con posterioridad a ella. Se les ha situado entre el Carbonífero y el Pérmico ya que "parecen intrusivos en los "stocks" de rocas prehercínicas y algunos plutones muestran una deformación muy penetrante tal vez ligada a la fase 3 de la deformación hercínica", (FUSTER, 1988: 29). Estas adamellitas destacan por sus colores claros, grisáceos (cuando es abundante el cuarzo y la biotita) y rosados, pues las micas se encuentran oxidadas y los feldespatos se desagregan en superficie con la mano; por ello se conservan importantes recubrimientos de alteritas especialmente en las partes más bajas de las vertientes al coincidir con áreas de fracturas y, por tanto, con mayor humedad.

Sobre esta litología (que favorece la alteración al estar frecuentemente afectada por diaclasas) se configura una gran variedad morfológica. Así, debido al predominio de diaclasas subhorizontales, es frecuente la manifestación en el paisaje de esta roca constituyendo dorsos de ballena, como las masas rocosas de Cabeza Fuente (1.587 m.) y Cabeza Mesá (1.678 m.); sobre ellas se desarrolla una de las vertientes curvas más características de La Sierra de Ávila, formada sobre este tipo de granito de grano medio, de tonalidad gris. Cuando el diaclasado dominante es de tipo ortogonal y debido a la fácil alteración de esta roca, su presencia en la topografía viene marcada por la abundancia de la roca "in situ", con resaltes rocosos destacados, los denominados berrocales, por lo que es frecuente la morfología de bolos y, en zonas de topografía de menor pendiente, de tors que culminan de forma irregular en piedras caballeras. La fácil desagregación de esta masa rocosa, fuertemente compartimentada por fracturas, parece que también ha favorecido la apertura de collados y la presencia de alteritas o surcos de arenización entre los afloramientos graníticos, siguiendo las líneas de fractura, por lo que 
están recubiertos por alteritas y por arenas gruesas procedentes de la propia erosión mecánica.

\section{1.c. Granitoides de grano grueso: Leucogranitos.}

Constituyen los granitos de La Serrota, un afloramiento en los alrededores del Puerto de Villatoro y un enclave en La Paramera (en el piedemonte de la Sierra de Los Baldíos, entre Palacios y Sotalvo). Se trata de granitoides de grano grueso a muy grueso, apreciándose cuarzo de hasta 1 ó $2 \mathrm{~cm}$. de diámetro y grandes gabarros de tonos rosados ( 2 a $4 \mathrm{~cm}$.), por lo que es conocido popularmente como "granito de pata de cabra".

Estos granitoides se caracterizan por su carácter leucocrático, es decir, por la abundancia de minerales de los llamados "blancos", granulométricamente por su textura porfídica, pero la nota más característica es una mayor resistencia a la erosión respecto a las adamellitas y una fuerte tendencia a la fracturación curva. Dichas características permiten que sobre ellos se desarrollen las mejores formas graníticas dirigidas por este tipo de estructura, siendo notable su disyunción en lajas o formas poliédricas, lo que les da un aspecto masivo. Así, sobre el conjunto de los granitos de esta unidad se desarrollan modelados en lajas o lanchares curvos de los escalones o en la culminación del relieve, formando los dorsos en las laderas de perfil convexo, que incluso dan nombre a parajes como Las Lanchas. Además, sobre estos granitos de "pata de cabra" es frecuente el desarrollo de microformas graníticas, pues en ellos confluyen una serie de factores, como sus propias características litológicas (grano grueso, mayor riqueza en feldespatos alterables) combinadas con la presencia de áreas de debilidad en la roca (cruces de diaclasas, áreas de trituración) y con una topografía favorable a la retención de agua, por lo que es habitual la presencia de formas de alteración alveolar o taffonis, junto con pilancones y estrías.

Los taffonis son oquedades o alveolos desarrollados sobre masas rocosas graníticas. Estas formas menores se localizan especialmente en la umbría de Matallana (entre Palacios y Sotalvo), así como en algunos sectores ubicados a media ladera (orientada hacia el norte) de La Serrota. En ambos casos, los taffonis aparecen sobre paredes verticales de grandes bloques caídos sobre masas de granito arenizado, base que parece proporcionar una mayor humedad para su desarrollo siendo, además, de mayor envergadura las oquedades en las zonas que permanecen en sombra durante más tiempo (FOTO 1).

Los pilancones se configuran sobre superficies horizontales, con capacidad para retener agua (de lluvia o procedente del deshielo), lo que favorece la alteración de micas y feldespatos; si a esto unimos la acción hielo-deshielo, la desagregación granular en las paredes se intensifica, dando la característica forma cóncava. En la Cuenca Alta del Adaja la distribución geográfica de los pilancones es extensa, aunque es frecuente localizarlos en las rampas inferiores desarrolladas en una litología más degradada y porosa. Estas microformas suelen ser poco pofundas, de superficie cóncava, modelado rugoso y con presencia habitual de canales de egresión. 
Foto 1. En la Umbría de Matallana (Sotalvo) es frecuente apreciar el desarrollo de teffonis sobre granotoides de textura gruesa, donde se observa el proceso de evacuación del manto de arenización po efecto de hidratación y la escamación producida por el retoque de agentes externos (viento, precipitación).

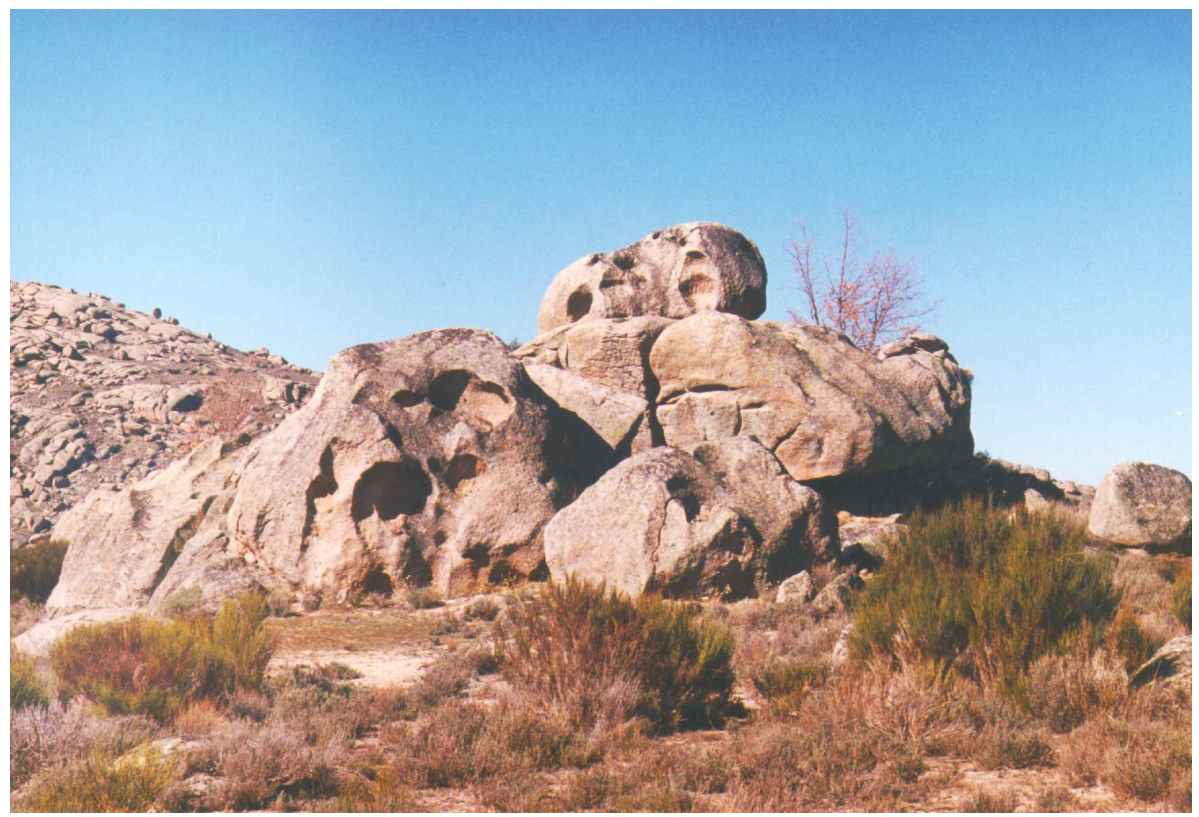

Las estrías o surcos se desarrollan por el drenaje de las aguas de escorrentía sobre la superficie de la roca. Estas estrías parecen arañazos sobre la masa rocosa y frecuentemente nacen a partir de los canales de desagüe que se inician en los pilancones culminantes y siguen a lo largo de las vertientes graníticas curvas, constituyendo pequeños canalillos que otorgan a los canchos y a los muros un aspecto de piel rugosa. Son, por tanto, canales estrechos y profundos cuya superficie manifiesta los efectos de desagregación y alteración del granito, más que el alisamiento producido por corrientes de agua.

\section{1.d. El caleño: alteración de granitos.}

En el borde norte del Valle Amblés aparecen pequeños afloramientos de una roca que recibe la denominación local de "caleño" (FOTO 2). Esta roca granuda, de aspecto areniscoso, destaca en el conjunto por sus tonos variables, que van del blanco lechoso al rojo granate. En los bordes de los afloramientos surge una especie de bandeado, con predominio de colores blancos y amarillentos en una roca muy porosa, sobre la que destacan dos bandas de color rosado y amarillento, de rocas aparentemente menos porosas y mayor tamaño de grano, que engloban un núcleo de color amarillo intenso. Morfológicamente, estos afloramientos de cale- 
ño quedan en resalte al ser zonas de mayor resistencia a la erosión, pues tienen mayor cohesión y dureza debido a la presencia de un cemento silíceo que compacta los granos y los conglomerados de pequeños cantos de cuarzo. Dicha roca, de características singulares por su coloración y textura, presenta una génesis poco precisa a la que se le han atribuido diversos orígenes:

Foto 2. Detalle del “caleño”, destacando sobre la clásica tonalidad gris del granito fresco.



- Tectónico: Esta teoría se apoya en la situación de los afloramientos de caleño, pues se encuentran prácticamente en la intersección de la gran falla que limita el horst de Ávila y el Valle Amblés, con fallas menores de dirección NNE-SSW. Según ARENILLAS $(1976: 2,4)$ estas rocas corresponden "a una serie de paquetes de areniscas arcósicas de variada tonalidad... La dirección de los bancos ees WNW-ESE, que coincide aquí con la de las fallas de borde de la depresión".

- Hidrotermal: Esta teoría, indica que estas rocas se han podido producir como "consecuencia de acciones hidrotermales acompañadas de procesos de silicificación sobre materiales muy diferentes, rocas granitoideas, diques y sedimentos detríticos) pero que tienen en común estar situados cerca de zonas de fractura". (UBANELL ET AL, 1978: 158). En posteriores artículos, ${ }^{2}$ dichos autores muestran

${ }^{2}$ GARZÓN HEYDT, G; UbANELL, A.G. Y RosAles, F. (1981): «Morfoestructura y sedimentación terciarias en el Valle Amblés (Sistema Central Español)». Cuadernos de Geología Ibérica, vol 7. 
la existencia de otros afloramientos, a favor de la falla Alentejo-Plasencia (en Muñico, Monsalupe) y a favor de la falla de Amblés en el Cerro Hervero.

- Ígneo: Según otras interpretaciones en investigación destaca la hipótesis según la cual "durante el Mesozoico una gran parte de este zócalo permaneció emergida, sufriendo importantes alteraciones de carácter tropical cuyos restos aparecen desnivelados, truncados y/o fosilizados por sedimentos de diferentes edades y naturaleza. Relacionados con estas alteraciones existen silicificaciones, ferruginizaciones, argilizaciones... que han dado como resultado litologías particulares" (MOLINA, 1993: 83).

Pero, además del origen poco preciso, los autores tampoco se ponen de acuerdo en el tipo de material. Quien lo menciona por primera vez es MARTín DONAYRE (1879: 294), que los calificó como argilófiros, es decir, "roca feldespática alterada, con grano de cuarzo y en ocasiones con nódulos ferruginosos rojizos y una sustancia opalina de brillo resinoso. Los colores de la roca varían entre tonos blanquecinos, amarillentos, violados y rojizos". Ya en 1976, ARENILLAS, ${ }^{3}$ al analizar el afloramiento de la cantera vieja de Ávila y el de La Colilla, llega a la conclusión de que esta roca es de origen sedimentario y posiblemente de edad Paleógena. En esta misma línea otros investigadores, indican que dichos materiales "presentan las características típicas de las areniscas feldespáticas, probablemente miocenas de la Cuenca del Duero, con las facies de borde más groseras, ricas en cantos, y con niveles ligeramente cementados" (UBANELL et al., 1978: 153). Idea que sigue presente en otros artículos que encuadran estos afloramientos dispersos dentro del "ciclo sedimentario de las areniscas silíceas", indicando que los depósitos están "constituidos por areniscas de grano grueso y conglomerados de cantos pequeños de matriz arcilloferruginosa y clastos fundamentalmente de cuarzo... Esta formación presenta una gran cohesión y dureza y unas características manchas de colores ocres y violáceos, que afectan también a las rocas graniticas y porfidicas inmediatas a estos afloramientos... La interpretación de estos hechos lleva a la conclusión de que estos materiales han sufrido una serie de procesos locales de silicificación y caolinitización que también han afectado al sustrato granitico" (GARZÓN HEYDT, G. et al, 1981: 662).

Algunos autores, indicaron que ese material de gran dureza debió sufrir procesos de silicificación y ferruginización edáficos que "afectan a antiguos regolitos graníticos, en los que es perfectamente visible la anterior textura ignea fosilizada por el ópalo [.......] En superficie se diferencian areniscas ricas en cuarzo detrítico, conglomerados y depósitos de canal, todos con una silicificación notoria [.../...] Presentan concreciones ferruginosas, interpretadas como indicios de oscilaciones del nivel freático durante la opalinización", indicando al mismo tiempo que la precipitación del ópalo en la estación seca favorecía un proceso de hidromorfismo moderado, (SAAVEDRA et al., 1985: 437).

En definitiva, parece que este tipo de rocas de aspecto opalino, con colores

\footnotetext{
Madrid: p. 662.

${ }^{3}$ Arenillas, M. (1976): «Nota acerca de dos afloramientos del Paleógeno en el Valle Amblés (Ávila). Empleo de sus materiales en la construcción». Tecniterrae, $\mathrm{n}^{\circ}$ 10: 8-14.
} 
abigarrados y dureza se encuentran en el contacto con las rocas sedimentarias. Dicho aspecto ha sido puesto de manifiesto por UBANELL (1978: 157) cuando afirma "que el primer tipo (afloramientos de La Colilla) se ha formado por transformaciones (caolinitización y silicificación) de rocas graníticas y/o diques porfidicos"; esta teoría ha sido apoyada por SAAVEDRA (1985) y ratificada en las últimas investigaciones llevadas a cabo por MOLINA BALLESTEROS $(1993)^{5}$ al indicar que la alteración del zócalo y la silicificación a techo se produjeron en dos momentos climáticos diferentes: la alteración en condiciones más húmedas y la silicificación en situaciones de carácter estacional y con tendencia a la aridez.

Desde nuestra modesta opinión, creemos que esta roca conocida como "caleño" no es ni una arenisca cementada ni tampoco una caliza, sino simplemente granito arenizado, en cuyo origen intervienen varios factores, entre ellos el tectónico a nivel interno, pero también a nivel superficial agentes externos como el agua. Así, este granito más o menos triturado por los ajustes tectónicos ha sufrido fluctuaciones de agua superficial, lo que ha supuesto la oxidación de la roca. Este hecho explica la apariencia de la roca tanto en su textura (la meteorización ha contribuido a que la roca se asemeje más a una arenisca que al propio granito), como en sus coloraciones, que van desde el ocre-amarillo al rojo-granate; esta singularidad cromática explica el uso ornamental de la misma en la arquitectura monumental de Ávila (Girola de la Catedral de Ávila, San Pedro...). Esta misma premisa aparece en el Mapa Geológico y Minero de Castilla y León cuando indica que "un material intermedio entre una arenisca y un granito es la silcreta llamada caleño, que se utilizó en los monumentos de Ávila, y se obtenía de las canteras de La Colilla, hoy dia abandonadas". (SIEMCALSA, 1997: 237).

Los afloramientos de caleño más característicos son los situados al este de la Colilla y en los alrededores de Ávila. En el primero, destacan las canteras localizadas al este del pueblo, tratándose de rocas con numerosas venas, de tonos rojoamarillentos. En el segundo, (afloramiento del Cerro Hervero, al noreste de Ávila capital) el caleño se desarrolla sobre la gran banda de diques este-oeste de pórfidos sobre la que se asienta la ciudad. En cambio, en el yacimiento situado al sureste de la capital (situado a 1,5 Km. de Ávila -El Escorial en la C. 505) aparecen afloramientos discontinuos entre zonas de granito fresco y material sedimentario. Dichos afloramientos de "caleño", se encuentran dispersos en el borde norte del Valle Amblés, en las cercanías de Ávila, por lo que han sido aprovechados para la construcción de la arquitectura monumental de la capital. Este aspecto ya fue comentado por F. DE LAS BARRAS (1903: 110-111) cuando manifestó que en "algunos sitios, la alteración del feldespato ha dado lugar a un argilófiro, teñido de sales de hierro y manganeso, que ha servido para la construcción de los mo-

\footnotetext{
${ }^{4}$ SAAVEDRA et al. (1985): Opus cit: p. 437, indican que "La mayoría de las silificaciones del área afectan a antiguos regolitos graníticos"

${ }^{5}$ Este autor afirma que "en los alrededores de Ávila el Macizo Hercínico Ibérico conserva los restos de un antiguo manto de alteración superficial en el que es posible distinguir 3 niveles de alteración: a) el inferior o de bolos, b) el intermedio de color ocre y rico en esmectitas y c) el superior rico en kaolionitas y ópalo”. MOLINA BALLESTEROS, E. (1993): «Incidencia de las alteraciones del zócalo hercínico ibérico en las características de las rocas afectadas, empleadas como materiales de construcción. Los granitos de La Colilla (Ávila)» Opus cit.: p. 87.
} 
numentos principales de Ávila", entre los que destacan el ábside de la catedral de Ávila, San Vicente, San Pedro... En esta misma línea continúan las investigaciones realizadas dentro del Programa STEP $1991-94,{ }^{6}$ cuyo objetivo fue el estudio de las rocas graníticas empleadas como materiales de construcción, haciendo referencia en estos artículos al material empleado en la edificación de la catedral de Ávila. En la actualidad, estas canteras están dentro del Inventario del ITGME como puntos geológico-mineros de interés singular, incluso como medida complementaria podría declararse alguno como reserva del Estado, debido a su interés como material para la restauración de monumentos de Ávila. A nuestro entender, deberían entrar en esta categoría los afloramientos ubicados en el Km.1,5 de la C-505 y el de La Colilla; el primero porque conserva una escombrera del siglo XII, un frente de cantera y al mismo tiempo es el más amenazado por las construcciones suburbanas de Ávila, y el segundo ya que posee una amplia superficie de yacimiento y presenta unas tonalidades más vivas "piedra-sangrante".

\subsection{Rocas Filonianas.}

En la topografía de la Cuenca Alta del Adaja destacan resaltes rocosos en forma de "sierros o serretas", desarrollados sobre diques de rocas filonianas que parecen haberse intruido en relación con importantes líneas de fracturación, insertándose en las rocas graníticas. En nuestra zona de estudio aparecen varios tipos de estas rocas, así en La Cuerda de Los Polvisos, en La Paramera y en La Sierra de Ávila (sirviendo de cimiento a las murallas), destacan las familias de pórfidos granítico-adamellíticos (de dirección aproximada $\mathrm{E}-\mathrm{W}$, aunque localmente sufren desviaciones que los sitúan en una posición SE-NW) (FOTO3). Estos diques de tonos claros, al ser más resistentes a la erosión que las rocas graníticas encajantes, forman las características barras rocosas que resaltan sobre las culminaciones romas típicas de las sierras.

Desde el punto de vista morfológico destaca el dique de gabro AlentejoPlasencia que, con una dirección NE-Sw, aparece en nuestra zona de estudio en las inmediaciones del Puerto de Villatoro (1.399 m.) donde se observa nítidamente debido a la ampliación de la carretera Ávila-Plasencia, apreciándose dos ramas de tendencia paralela en las cercanías de Poveda y de Pascual Muñoz. (FOTO 4). Morfológicamente, este dique de gabro parece dirigir las alineaciones de la parte occidental de La Sierra de Ávila desde el Risco (1.581 m.), en Amavida, al Risco del Viso (1.585 m.), cerca de Balbarda; además, en relación con este dique se conservan cerros elevados sobre el nivel de glacis. Litológicamente, se encuentra constituido por diabasas, gabros normales, gabros de grano grueso, lo que le confiere su característico color negro. Según UBANELL (1977: 200) su evo-

\footnotetext{
${ }^{6}$ GarCía TAlegGón, J.; IÑIGO, A.C.; Molina, E.; Rives, V. Y Vicente, M.A. (1993): «Granitos empleados en la catedral de Ávila: características de los materiales de cantera». Actas del Workshop, Alteración de granitos y rocas afines empleadas como materiales de construcción. CSIC, Madrid: 125-127. García Talegón, J.; García del Amo, D.; IÑIgO, A.C.; Menduiña, J.; Molina, E. Y VICENTE, M.A. (1993): «Propiedades físico-mecánicas de los granitos empleados en la catedral de Ávila procedentes del yacimiento de "La Colilla (Ávila)"». Actas del Workshop, Alteración de granitos y rocas afines empleadas como materiales de construcción. Csic, Madrid: 129-132.
} 
lución estructural es muy compleja al "haber sufrido efectos tectónicos posteriores a su emplazamiento con cortos desplazamientos, o procesos de trituración por los sistemas E-Wy NNW por lo que la falla de Plasencia ha jugado de nuevo, apartándose en algunos lugares... apreciándose dislocaciones según fallas paralelas o no a la principal mientras que éstas se traducen en un arqueamiento de la estructura". Mientras que otros autores afirman que "queda claro que es un sistema de fracturación que ha funcionado con posterioridad a la intrusión del dique. Seguramente en épocas recientes puesto que en el Km. 21,65 del F.C. de Avila a Salamanca puede observarse cómo el granito monta sobre un Terciario reciente constituido por conglomerados arcósicos que por cierto contiene cantos pertenecientes al dique básico. Además hay desplazamientos locales con dirección $N 30^{\circ} \mathrm{W}-40^{\circ} \mathrm{W}$ y entre ambos pueden formar un sistema conjugado)", (GARCÍA DE FIGUEROLA Y CARNICERO, 1973: 75).

Foto 3. Los diques de pórfido granítico-adamellíticos de dirección $E-W$ al ser más resistentes que la roca encajante dan un relieve en resalte formando barras rocosas, que han servido de cimiento a las murallas de Ávila.

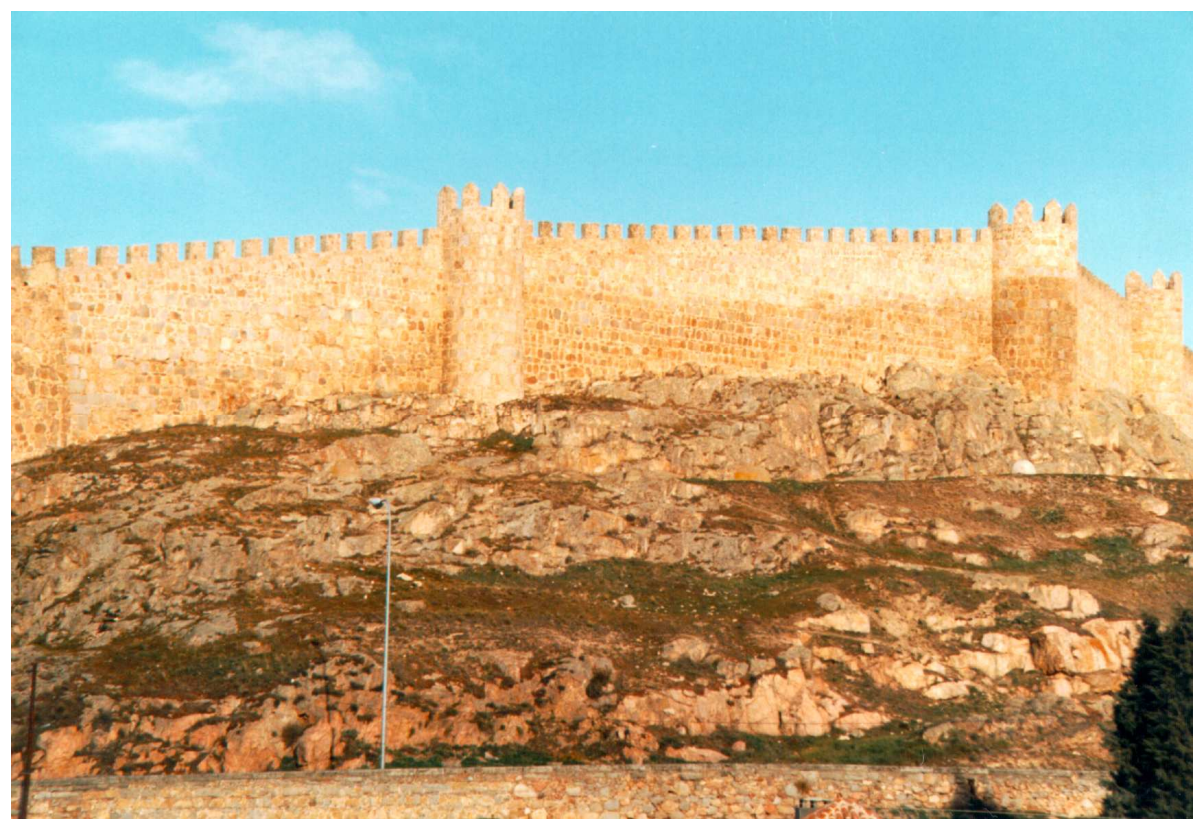

En La Serrota y en La Sierra de Ávila también es frecuente observar diques de episienitas o sienitas (NNE-SSW),rocas plutónicas de tonos enrojecidos en los que se ha producido una migración del cuarzo a expensas del desarrollo de feldespatos, de ahí que presenten un color rojo-rosado. Según ARENILLAS et al. (1975: 241), "parece que se produjo por emigración de disoluciones hidrotermales en- 
riquecidas en sodio a través de probables fracturas desarrolladas en la roca cuando aún estaba consolidándose". Entre este tipo de rocas destaca el dique sienítico de carácter alcalino de Las Fuentes (Muñana), tanto por ser una morfología de resistencia (ofreciendo el típico relieve en barra rocosa bastante alterada), como por su color rojo, producido por un "efecto combinado de la génesis de un tipo determinado de magma granítico y de su emplazamiento, en la etapa final de la actuación enérgica de fallas de desgarre tardihercínicas... El resultado de tal síntesis estaría en una fusión parcial reducida de rocas mantélicas mientras que su concentración se debería a una baja de presión y al desarrollo de fallas distensivas secundarias, algunas de ellas profundas y canalizadoras tanto de los fluidos alcalinos como de ciertas rocas básicas asociadas", (SAAVEDRA Y ARENILLAS, 1979: 555).

La morfología característica de este tipo de material es producto de la destrucción de la barra rocosa, por lo que aparecen apilamientos "rectilíneos" de bloques, pues aunque esta roca se presenta fuertemente fracturada, sin embargo resiste a la erosión dando una morfología de resalte a modo de crestería, como el que constituye la culminación del Alto de Las Fuentes $(1.630 \mathrm{~m}$.) o el Alto del Cerro de Gorría (1.728 m.).

Foto 4. El dique de gabro Alentejo-Plasencia atraviesa la Sierra de ávila en dirección NE-SW desde el puerto de Villatoro hasta las inmediaciones de Muñana, pudiendo ser detectado en algunos puntos por su característico color negro.

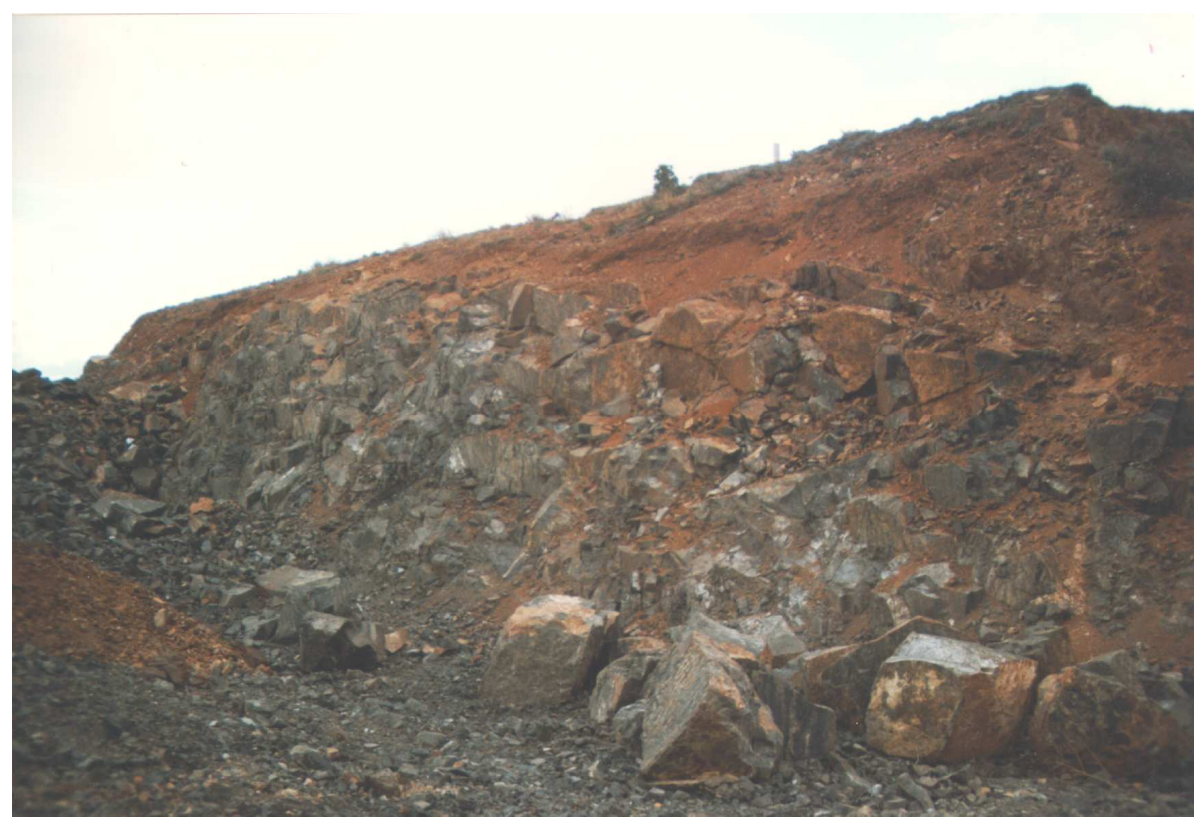


Entre los numerosos diques de dirección NE-SW, destacan los de cuarzo lechoso que, a pesar de su pequeño tamaño sobresalen en el paisaje como líneas de resalte de color blanco conocidas como "sierros". Los diques de lamprófidos de dirección NNE-SSW tienen un característico color gris verdoso y con frecuencia están muy rotos y erosionados en superficie, por lo que sólo aparecen claramente "in situ" en pequeños afloramientos de La Cuerda de Los Polvisos y en La Paramera, como el afloramiento básico localizado en un collado al este del Pico Zapatero, descrito como "materiales de origen volcánico efusivo de color verde oscuro" (UBANELL Y ROSALES, 1983: 432).

\section{SEDIMENTOS TERCIARIOS.}

Frente a los materiales del zócalo, característicos de los bordes montañosos, en la depresión del Amblés dominan depósitos detríticos procedentes de la denudación del zócalo granítico y metamórfico, pues la sedimentación de la Fosa ha estado controlada por el comportamiento geodinámico de sus bordes y por los materiales de las áreas madres que la orlan, estando constituidos estos sedimentos por facies arcósicas. A estos depósitos se les atribuyó un origen Neógeno, aunque ante el hallazgo de un yacimiento de vertebrados en Los Barros (al sureste de Ávila capital), fueron datados como pertenecientes al Paleógeno, Oligoceno medio (GARZÓN HEYDT y LÓPEZ, 1978: 575).

La mayor parte de la depresión del Amblés está ocupada por sedimentos arcósicos de color ocre frente a los limos más oscuros, pues según un estudio "en el Valle Amblés las arcosas alternan con niveles limosos tanto en distribución lateral como vertical; localmente estos limos pasan lateralmente a arcillas, siendo el espesor de estos niveles del orden de 5 a 6 m. como máximo", (Compañía General de Sondeos, 1976: 11). En 1984 PORTERO $^{7}$ pone de manifiesto una mayor diversidad en la composición litológica del Valle de Amblés, en el que "existen areniscas silíceas, caoliníticas y ferruginosas, sobre las que reposan, mediante suave discordancia, potentes niveles de arcosas poco evolucionadas, depositadas mediante sistemas de abanicos aluviales con predominio de facies de transporte en masa y canales distribuidores efimeros. Hacia su techo estas arcosas han sido datadas como Oligoceno medio en el Valle Amblés". Pero es en el estudio realizado por GARZÓN, UBANELL Y ROSALES (1981), ${ }^{8}$ donde se realiza un análisis detallado de los sedimentos del Valle Amblés en relación con las cuencas próximas, distinguiendo dos ciclos sedimentarios: el ciclo sedimentario de las areniscas silíceas y el ciclo sedimentario de las arcosas y, a su vez, dentro del segundo dos facies: una facies de conglomerado poligénico y otra facies arcósica.

Estos materiales de carácter continental tienen su origen en procesos de meteorización física y química; probablemente fueron depositados en un clima árido bajo un régimen de escorrentías esporádicas, pero torrenciales, de gran capacidad

\footnotetext{
${ }^{7}$ PorTERo et al. (1984): «Evolución morfotectónica y sedimentación Terciarias en el Sistema Central y Cuencas limítrofes (Duero y Tajo)». I Congreso español de Geología, T. III: 253-263.

${ }^{8}$ Garzón Heydt, G., Ubanell, A.G. y Rosales, F. (1981): «Morfoestructura y sedimentación Terciarias en el Valle Amblés (Sistema Central Español». Cuadernos de Geología Ibérica, vol. 7: 661-663.
} 
de erosión y transporte, arrastrando estos materiales hasta las cuencas continentales, donde se sedimentaban en forma de abanicos aluviales con distribución radial hacia el centro de la misma, lo que explica la variación del tamaño de las partículas, que van desde conglomerados y bloques, en las zonas de borde de la cuenca, hasta sedimentos más finos (arcosas con intercalaciones de tramos arcillosos y limosos), en el centro de la misma. De ahí, que el mayor contenido de arcillas se encuentre en la zona norte de la depresión (excepto el depósito relacionado con la Sierra de Yemas), disminuyendo hacia el sur y este, mientras que los niveles groseros muestran un mayor desarrollo hacia el sur de la depresión. Esa distribución de las arcosas en facies proximales más groseras, y distales más finas, de acuerdo con los volúmenes montañosos actuales, parece indicar que durante su deposición, el Valle Amblés ya estaba inicialmente configurado.

A lo largo del borde oeste del Valle Amblés (al sur de Pradosegar, al oeste de Guareña, al sur de Muñotello, al sureste del Adaja y al sureste de Blacha) y también en el borde sur (al este de Aldea del Rey Niño junto al cauce del arroyo Gemional y al noreste de Gemuño), se pueden apreciar depósitos detríticos gruesos, heterométricos, formados por grandes bloques, cantos y arcosas de carácter anguloso. Estos sedimentos de carácter continental tienen su origen (Neógeno) en procesos de meteorización mecánica que provocaban la denudación del zócalo, por lo que es frecuente observar cantos de granito, pórfido, cuarzo y materiales metamórficos que pueden alcanzar hasta el tamaño de bolos; la gran dimensión de estos bloques parece indicar que el medio donde se depositaron requeriría un transporte de alta energía para movilizar bloques de ese tamaño. Así, podemos distinguir arcosas amarillentas de grano medio a grueso, mal seleccionadas, con cantos y algún bloque disperso de granito redondeado y muy alterado (20 a 30 $\mathrm{cm}$.) con intercalaciones de arenas muy gruesas y mal seleccionadas o niveles de gravas presentando por tanto gran similitud con las alteritas graníticas. En superficie, la mayor parte de la extensión de estos afloramientos aparecen semicubiertos por derrubios de ladera superficiales y muchos bloques graníticos están arenizados "in situ", destacando superficialmente los de cuarzo, como se aprecia en el Cerro Barbas (Baterna) donde sobresale el gran tamaño de los bloques que llegan incluso a alcanzar el metro de diámetro, estando algunos de estos bloques graníticos arenizados.

En cambio, a medida que nos acercamos al centro de la cuenca se pasa a arcosas más evolucionadas, más finas, aumentando las intercalaciones limoarcillosas y arcillosas, por lo que las arcosas presentan manchas de colores rojizos o pardos. Es aquí donde se encontraba situado el yacimiento de vertebrados de Los Barros, que, como ya indicamos, permitió datar a estos sedimentos como pertenecientes al Oligoceno medio. Estas arcillas constituyen extensos niveles, siendo explotadas la mayor parte para abastecer a las tejeras de Ávila, al ser utilizadas como materia prima para la realización de tejas y ladrillos. Se extraen en los "Barreros" sitos al S y SE de Ávila (Dehesa Canecera), en las proximidades de Gemuño y al pie de la Sierra de Yemas.

Topográficamente, hemos de indicar que estos materiales terciarios -fáciles de erosionar debido a su escasa cohesión- presentan una morfología subhorizontal, típica de las campiñas que caracterizan el paisaje de la fosa del Amblés, apenas 
interrumpida por suaves ondulaciones desarrolladas en los depósitos de bloques, cantos y arcosas. Entre estas elevaciones, que apenas resaltan 30 metros sobre la llanura circundante, destacan el Cerro Barbas, en Baterna a 1.168 m., y el Cerro de Aldeavieja, en El Fresno con 1.092 metros.

\section{DEPÓSITOS DE RECUBRIMIENTO CUATERNARIOS.}

Los depósitos del Cuaternario se disponen en afloramientos dispersos por toda la Cuenca produciendo los últimos retoques en el relieve a partir de procesos glaciares, fluviales, gravitacionales etc. Nosotros, de forma esquemática, hemos clasificado las formas de recubrimiento cuaternarias en los siguientes grupos fundamentales:

\subsection{Depósitos glaciares y asociados.}

La acción glaciar aparece concentrada únicamente en La Serrota, desarrollándose las formas glaciares por encima del nivel de las nieves perpetuas $(>1.700$ $\mathrm{m}$.). Los depósitos glaciares presentan una morfología de morrenas bien conservadas. Desde el punto de vista sedimentológico, se trata de "tills" con abundancia de bloques muy heterométricos, mal seleccionados, junto a cantos englobados en una matriz arenosa poco o nada redondeada, lo que parece indicar que fueron abandonados en un proceso de fusión rápida. El gran tamaño y escaso desgaste de buena parte de estos bloques morrénicos evidencian su origen crioclástico. Estos depósitos de conglomerados heterométricos, más o menos angulosos con cantos de las morrenas laterales, aparecen asociadas en La Serrota a los cinco "glaciares de circo y nichos de nivación" Pleistocenos (fase de Würm alpina).

El fondo de los valles glaciares aparece cubierto de depósitos fluvioperiglaciares, producto de la removilización y breve transporte de los depósitos morrénicos, sobre los que han actuado procesos de gelifluxión y gravitatorios asistidos por las aguas de escorrentía, por lo que aparecen coluviones empastados en una matriz arcillosa que actualmente está siendo cortada por los regatos que la atraviesan. Por encima de los $1.700 \mathrm{~m}$., en algunas zonas de La Serrota y Parameras, aprovechando las depresiones de antiguos valles y cuencas glaciares y en pequeñas hondonadas tipo nava, se localizan algunos depósitos de turbera, de dimensiones muy reducidas. Parecen estar relacionados con procesos de solifluxión, asociados a suelos periglaciares de césped almohadillado y de mayor hidromorfismo, dado que estos materiales están asociados a manantiales, con procesos de encharcamiento donde son frecuentes los procesos de acumulación de materia orgánica.

\subsection{Materiales de origen gravitacional.}

Las laderas y taludes de los bordes montañosos aparecen tapizadas por un conjunto heterogéneo de materiales de origen gravitacional procedentes de la descomposición de los macizos graníticos y metamórficos. A pesar de su diversidad, estos depósitos presentan como característica común su génesis asociada al 
modelado periglaciar (Pleistoceno) con predominio de procesos gravitacionales, asistidos por fenómenos de arroyada, solifluxión. Entre este conjunto variado podemos distinguir: coluviones, eluviones y conglomerados.

Los depósitos coluviales representan un conjunto heterogéneo de derrubios heterométricos de granulometría diversa, aunque en general con predominio de cantos y gravas de naturaleza casi siempre granítica, empastados en una matriz que en las áreas más superficiales es muy arenosa. Proceden de la ruptura directa de las rocas y de la transformación de los depósitos anteriores (morrenas, berrocales...) por acción del hielo-deshielo; la actuación de la crioclastia ha hecho que los bloques se rompan, mientras que la matriz que los envuelve procede de la alteración de las micas y feldespatos por empapamiento del sustrato y también de la microcrioclastia que las heladas provocan en su penetración en el suelo. Posteriormente, estos coluviones se han desplazado de sus lugares de origen ayudados por procesos de solifluxión, gelifluxión y reptación. Dichos depósitos forman la mayor parte de la morfología periglaciar de cumbres y altas vertientes, rellenando las cuencas de recepción o cabeceras de arroyos y valles en cuna periglaciares de fondo muy amplio, e incluso las formas planas y convexas de cumbres alomadas aparecen cubiertas por esta formación superficial, excepto en las áreas rocosas. También se presentan tapizando las vertientes con materiales de granulometría dominantemente fina, asociados a los fenómenos solifluidales.

En las zonas afectadas por fenómenos tectónicos, a lo largo de las líneas de fractura donde los procesos de meteorización han sido más intensos, se desarrollan depósitos de eluvión, producto de la alteración del granito, por lo que aparecen alteritas de niveles más o menos finos con inclusiones de bloques de tamaño variado de la roca madre, por lo que su composición varía de arcósica a limoarenosa y de materiales limo-arcillosos con cantos. Morfológicamente, estos materiales forman los característicos pasillos de alteración.

Las morfologías de glacis aparecen desarrolladas sobre depósitos conglomeráticos (de edad pleistocena-holocena) con grandes bloques y arcosas, limos y gravas poco organizadas con abundante matriz. Estos derrubios han sido formados a expensas de la arenización de los granitoides, constituyendo depósitos gravitacionales o de arroyada que articulan las vertientes montañosas con los fondos de valle, dando la forma de relieve que genéricamente denominamos glacis.

\subsection{Los depósitos aluviales.}

Forman los fondos de valles actuales según un sistema de terrazas en el que se labra el cauce de los ríos principales. Constituidos por materiales gruesos, arenas, con acumulaciones locales de gravas y cantos presentan una composición litológica muy variada, pues dependen de la litología de sus áreas fuente. Así, los aluviales desarrollados en los arroyos que discurren sobre materiales graníticos, presentan unas arenas con un alto grado de desgaste, de color claro y composición generalmente cuarzosa y feldespática; por su parte los aluviales de aquellos arroyos que recorren el zócalo metamórfico, están compuestos por granos de morfología alargada y aspecto más bien oscuro. Estos depósitos de origen fluvial presentan la particularidad de tener mayor desarrollo en la margen derecha del río 
como respuesta a los mayores relieves del borde sur de la cuenca y la existencia de fallas en el zócalo. Los ríos que nacen en La Serrota y alta Paramera presentan una dinámica torrencial en función, en primer lugar de la pendiente. Es así que en la salida de sus torrentes o barrancos presentan la morfología de conos aluviales o de deyección de pequeña extensión, formados por materiales conglomeráticos (bloques, bolos y cantos y arcosas) con bastante buena selección de tamaños, bien redondeados y abundante matriz limosa. Suelen ser materiales gruesos, arenas, gravas, cantos y arenas de litología variada, dominando los más resistentes (cuarzo, aplitas, sienitas, gabros...), aunque también hay granitos y neises.

En los ríos y arroyos de dinámica más tranquila, donde las depresiones son mayores (Adaja, Ullaque, Río Mayor, Arroyo de Gemional...), abundan los depósitos aluviales constituidos por materiales más finos -limos, arcillas y en menor proporción arenas-, aunque pueden aparecer con un ligero tono grisáceo cuando han conservado algo de materia orgánica. Morfológicamente, estos sedimentos forman la llanura de inundación. En el río Adaja aparecen escalonados, sobre el canal actual y en varios niveles $(+4,+5,+6,+7 \mathrm{~m}$.), una serie de depósitos pleistocenos constituidos por materiales conglomeráticos formados por cantos poco $\mathrm{o}$ nada consolidados, bloques de escaso espesor con gravas, arenas y limos, cuya expresión morfológica son las terrazas fluviales. Estos depósitos cuaternarios de arenas y gravas son utilizados como áridos naturales en la construcción o como componente de hormigones, de ahí que sean abundantes las graveras a lo largo del curso del río Adaja.

\section{BIBLIOGRAFÍA.}

- ARENILLAS, M y SAAVEDRA, J. (1982): «Sobre la génesis y evolución de materiales silicificados prelutecineses del Centro-Oeste de España (provincias de Ávila, Salamanca y Zamora». Boletín del Servicio Geológico. no 42: 69-85.

- ARENILLAS, M. (1976): «Nota acerca de dos afloramientos del Paleógeno en el Valle Amblés (Ávila). Empleo de sus materiales en la construcción medieval abulense». Tecniterrae, $\mathrm{n}^{\mathrm{o}}$ 10: 1-7.

- ARENILlAS, M. et al (1975): «Un dique de tendencia sienítica en la provincia de Ávila». Boletín Geológico Minero, Tomo 86: 233-243.

- ARRIBAS, A. Y JIMÉNEZ, E. (1972): Memoria del mapa geológico de España, Escala 1:200.000, Ávila. IGME, no 44. Madrid.

- BARRAS, F. DE LAS (1903): «Algunas observaciones sobre los granitos de Ávila». En Boletín Real Sociedad Española de Historia Natural, n 3: 110-112.

- CAPOTE, R. (1968): «Paleozoico de los alrededores de Ávila». Estudios geológicos, $\mathrm{n}^{\mathrm{0}}$ 24: 181-189.

- COMPAÑÍA GENERAL DE SONDEOS S.A. (1976): Estudio Geológico-minero de la Fosa del Amblés y fase previa de investigación con sondeos. Documento interno. Junta de Castilla y León. Inédito.

- FUSTER, J.M. et al. (1988): «El complejo plutónico hercínico y tardihercínico del Sistema Central Español». En BEA, F.; CARNICERO, A.; GONZALO J.C.; LÓPEZ PlazA M. y RodRÍGUEZ Alonso M.D. (eds.): Libro Homenaje a L.C. 
GARCÍA DE FIGUEROLA. Madrid Ed. Rueda: 27-35.

- FUSTER, J.M. Y MORA PEÑA, A. (1970): «El carácter del metamorfismo en el macizo de La Cañada (Sistema Central español)». Estudios Geológicos, vol. 26, $n^{0}$ 3: 317-321.

- GARCÍA DE FIGUEROLA, L.C Y CARNICERO, A. (1973): «El extremo noreste del gran dique Alentejo-Plasencia». Studia Geologica, VI: 73-84.

- GARCÍA DE FIGUEROLA et al. (1983): «Características petrológicas del complejo laminar pegamatoide ("serie del Álamo") de las provincias de Salamanca y Ávila». Studia Geologica Salmanticensia, XIX: 33-77.

- GARCÍA TALEGÓN, J.; IÑIGO, A.C.; MOLINA, E.; RIVES, V. Y VICENTE, M.A. (1993): «Granitos empleados en la catedral de Ávila: características de los materiales de cantera». En Actas del Workshop, Alteración de granitos y rocas afines empleadas como materiales de construcción. Madrid, CSIC: 125-128.

- García TAlegón, J.; GARCÍA DEl AmO, D.; IÑIGO, A.C.; MENDUIÑA, J.; MOLINA, E. Y VICENTE, M.A. (1993): «Propiedades físico-mecánicas de los granitos empleados en la catedral de Ávila procedentes del yacimiento de "La Colilla (Ávila)"». En Actas del Workshop, Alteración de granitos y rocas afines empleadas como materiales de construcción. Madrid, CSIC: 129-132.

- GARZÓN HEYDT et al (1978): «Los roedores fósiles de Los Barros (Ávila). Datación del Paleógeno continental en el Sistema Central». Estudios Geológicos, T.34: 571-575.

- GARZÓN HEYDT, G., UBANELL, A.G. Y ROSALES, F. (1981): «Morfoestructura y sedimentación terciarias en el Valle Amblés (Sistema Central Español)». Cuadernos de Geología Ibérica, vol 7: 655-665.

- MARTín DONAYRE (1879): Descripción fisica y geológica de la provincia de Ávila. Memoria del Instituto Geológico y Minero.

- MOLINA BALLESTEROS, E. (1993): «Incidencia de las alteraciones del zócalo hercínico ibérico en las características de las rocas afectadas, empleadas como materiales de construcción. Los granitos de La Colilla (Ávila)». En Actas del Workshop, Alteración de granitos y rocas afines empleadas como materiales de construcción. Madrid, CSIC: 83-92.

- SAAVEDRA, J. et Aal. (1985): «Las silicificaciones del valle de Amblés (inmediaciones de Ávila)». Boletín Geológico y Minero, Tomo 96: 437-443.

- SAAVEDRA, J Y ARENILLAS, M. (1982): «Fenómenos de alcalinización y enrojecimiento de algunos granitos hercínicos tardíos y rocas básicas asociadas del Sistema Central (provincias de Ávila y Salamanca). Posición en su medio geotectónico». En I Reunión sobre Geología de la Cuenca del Duero. Salamanca, 1979. Parte II, temas Geológico-mineros: IGME: 539-566.

- SieMCALSA (1997): Mapa geológico y minero de Castilla y León. Escala 1:400.000. SIEMCALSA. Valladolid.

- UBANELL, A. G. et al. (1978): «Estudio de procesos de alteración hidrotermal en rocas graníticas y sedimentarias (provincia de Ávila)». Estudios Geológicos, T. 34: 151-160.

- UBANELL, A.G. Y ROSALES, F. (1983): «Localización y estudio de un afloramiento básico efusivo en la Sierra de La Paramera (Ávila) Sistema Central español». Cuadernos de Geología Ibérica, nº 7: p. 431-437. 
- UBANELL, A.G. (1977): «Modelo de fracturación de la región central española basado en las imágenes obtenidas por satélite (ERTS-1 y LANDSAT-2». Studia Geologica XII: 195-206.

- UBANELL, A.G. (1977): «Significado estructural de los diferentes afloramientos graníticos en un área del Sistema Central Español». Boletín Geológico y Minero. Tomo 88 (5): 365-370.

RESUMEN: Prácticamente la totalidad de la cuenca alta del Adaja está formada por rocas plutónicas pertenecientes al zócalo Paleozoico o Macizo Hespérico, destacando "a priori" una aparente uniformidad litológica que sólo se rompe por la existencia de materiales metamórficos en algunas zonas y por la presencia de materiales sedimentarios en las áreas deprimidas: Así pues, en la cuenca alta del Adaja los materiales más antiguos están presentes en afloramientos de rocas metamórficas; entre los materiales hercínicos, destacan los granitoides y los resaltes rocosos en forma de "sierros o serretas", desarrollados sobre diques de rocas filonianas. Frente a los materiales del zócalo, característicos de los bordes montañosos, en la depresión del Amblés dominan depósitos detríticos procedentes de la denudación del zócalo granítico y metamórfico, estando constituidos estos sedimentos por facies arcósicas. Los depósitos de recubrimiento Cuaternarios varían desde depósitos glaciares, materiales de origen gravitacional hasta aluviales.

PALABRAS CLAVE: Granitoides, caleño, arcosas, depósitos de recubrimiento.

ABSTRACT: Practically the entirety of the high basin of the Adaja is formed by rocks plutónicas belonging to the baseboard Paleozoico or Solid Hespérico, highlighting "a priori" an apparent litologic uniformity that only breaks for the existence of metamorphic materials in some areas and for the presence of sedimentary materials in the depressed areas: therefore, in the high basin of the Adaja the oldest materials are present in blooming of metamorphic rocks; among the hercinic materials, they highlight the granitoides and you stand out them rocky in form of "sierros or serretas", developed on dikes of filonians roks. In front of the materials of the baseboard, characteristic of the mountainous borders, in the depression of the Amblés they dominate detritic deposits coming from the denudation of the granitic and metamorphic baseboard, being constituted these silts by facieses arcósicas. The deposits of Quaternary vary from glaciers deposits, materials of origin gravitacional until alluvial.

KEY WORDS: Granitoides, caleño, arcosas, deposits.

RÉSUMÉ: Pratiquement l'intégralité de la haute cuvette de l'Adaja est formée par rocs plutónics qui appartient à la plinthe Paleozoico ou Hespérico Solide, en mettant en valeur "a priori" de l'uniformité litologica apparent qui seulement casse pour l'existence de matières métamorphiques dans quelques régions et pour la présence de matières sédimentaires dans les régions en déclin: par conséquent, les plus vieilles matières sont présent dans fleurir de rocs métamorphiques dans la haute cuvette de l'Adaja; parmi l'hercínicos matériel, ils mettent en valeur le granitoides et vous ressortez d'eux branlant dans forme de "sierros ou serretas", a développé sur fossés de rocs filonianas. Devant les matières de la plinthe, caractéristique des frontières montagneuses, dans la dépression de l'Amblés qu'ils dominent detríticos qui vient du denudación de la plinthe graniteuse et métamorphique, être constitué ces limons par arcósicas du facieses, dépose. Les dépôts 
de recubrimiento Quaternaire varient de glaciers des dépôts, matières de gravitacional de l'origine jusqu'à alluvial.

MOTS-CLES: Granitoides, caleño, arcosas, dépôts. 